\title{
Website Localisation in the Corporate Context: A Spanish Perspective
}

\author{
María Dolores Olvera-Lobo, Celia Castillo-Rodríguez \\ University of Granada \\ Spain \\ molvera@ugr.es \\ celiacastillo@ugr.es
}

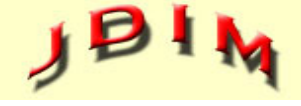

Journal of Digital Information Management

\begin{abstract}
Diverse factors such as the development of globalisation processes and an ever-changing economic environment are encouraging companies to access external markets. Localisation, the activity that makes a certain product -for example, a websitelinguistically and culturally appropriate for a particular country and language, is an extremely valuable tool for companies who want to pursue internationalisation strategies. In Spain, small and medium enterprises (SMEs) make up over 99\% of the country's business structure. However, the localisation of their websites is often deficient. An analysis of 70 Spanish SME corporate websites was performed with the purpose of assessing the degree and characteristics of website localisation in the SME sector in Spain. It was found out that the web presence of Spanish SMEs presents serious deficiencies and that the contents offered on their websites are often poorly localised, if at all. The information gathered enabled us to put forward a series of practical recommendations for SME corporate website localisation.
\end{abstract}

Subject Categories and Descriptors

H.5.3 [Group and Organization Interfaces] ; Web-based Interaction: J.1 [ADMINISTRATIVE DATA PROCESSING]; Business

General Terms: SME Websites, Website localization, Spanish Websites

Keywords: Localisation, Website Localisation, Translation, Small and Medium Enterprises (Smes), Spanish Smes, Gilt

Received: 28 September 2018, Revised 9 November 2018,
Accepted 28 November 2018

Review Metrics: Review Scale - 0/6, Review Score - 5.25, Interreviewer Consistency - 94.12\%

DOI: $10.6025 / \mathrm{jdim} / 2019 / 17 / 1 / 34-43$

\section{Introduction}

According to its most popular definition, put forward by the now defunct Localisation Industry Standard Association (LISA), localisation in translation is the activity that involves making a product linguistically and culturally appropriate for a locale, that is, the target country and language in which the product in question will be used and sold (LISA, 2003). Localisation is part of the set of interdependent processes known by the acronym GILT: Globalisation, Internationalisation, Localisation and Translation (Cadieux and Esselink, 2002). If observed individually, translation can be defined as the process by which the meaning of a text written in a source language is communicated through an equivalent text in the target language. Internationalisation comprises the identification and isolation of all local information that appears in a product (for example, dates, numbers, currency or contact information) in order to make its localisation faster and simpler. Finally, globalisation combines the processes of internationalisation and localisation. It involves changes in the organisation of the business structure so that it is possible to serve any customer and offer them products or services regardless of their language, region or culture (Lommel, 2007). This definition of globalisation is more 
often linked to the area of marketing. However, the concept of globalisation understood from a broader perspective is also undoubtedly relevant to the area of localisation: "a state of interconnectedness and interdependence descriptive of the increased international integration of trade, investment, finance, information and knowledge" (You, 2017).

Every localisation process consists of four basic components (Lommel, 2007). Firstly, there is an evident linguistic component, as made apparent by the close relationship that exists between localisation and translation. It also has a cultural component founded on the extensively described relationship between language, translation and culture. As Nida (1945: 194) points out, "the person who is engaged in translating from one language into another ought to be constantly aware of the contrast in the entire range of culture represented by the two languages". Hurtado Albir (2001: 607-608) further delves into this question by affirming that "translation occurs not only between two different languages, but also between two different cultures; translation is, therefore, intercultural communication. The transfer of cultural elements in a text is one of the biggest issues that the translator faces"1. Thirdly, there is a physical component that is not relevant in the case of website localisation since it refers to physical modifications -for example, the position of the steering wheel in a vehicle that will be marketed in the United Kingdom-. Finally, localisation presents a technical component. In most cases -although not always-, this process mainly consists in handling software products and it often involves stages such as manipulating graphical user interfaces or adapting visual content. These activities demand greater technical skills of translators-localizers than those required for "traditional" translation.

\section{Localisation and Internationalisation Processes: a Spanish Perspective}

In Spain, according to data published by the General Secretariat of Industry and Small and Medium Enterprises (2018), there are 2,842,783 registered businesses, of which 2,838,269 (99.8\%) are small and medium-sised enterprises (hereafter SMEs). In this context, websites are a medium of communication that can help companies establish new relationships with their target audience and do business in new ways. Some of the benefits that the use of a corporate website can provide for a company include real-time transactions, an increased visibility and competitiveness of the business, an improved corporate image and the elimination of intermediaries and geographical restrictions (Marín Dueñas and Lasso de la Vega, 2017).

Continuous transformations in the economic environment, where the acceleration of the globalisation process and the development of the knowledge economy act as drivers, are systematically pushing Spanish companies towards the challenge of accessing external markets. Website translation and localisation help promote the internationalisation of SMEs by closing the gap between Internet users from different socio-cultural and linguistic contexts. Likewise, localisation provides great benefits from a business perspective that far exceed the initial costs: several studies (Baack and Singh, 2007; Singh and Pereira, 2005) show that users spend up to twice as long on websites that have been localised into their first language, their attitude towards them is more positive and it is almost three times more likely that they end up purchasing a product.

In order to determine the current state of website localisation processes in the Spanish business environment, and more specifically in the case of its SMEs, we performed an analysis of the degree and characteristics of localisation on a sample comprising 70 corporate websites belonging to the same number of Spanish SMEs. These SMEs were included in the report 1000 Companies to Inspire Europe, a selection of businesses described as some of the most dynamic and fastest-growing in Europe (London Stock Exchange Group, 2017), and data were collected during the second half of February 2018. The results obtained show that there is still a long way to go for the online presence of Spanish SMEs and the localisation of their websites. This is evidenced by the fact that even companies at the forefront of the Spanish economy are not implementing localisation processes that match their level and relevance.

According to our analysis, although the majority of SMEs have localised their sites into several languages, these localisations present a considerable number of deficiencies such as: poor linguistic quality of target texts, with occasional signs of machine translation; many of these websites are only partially localised -often, certain areas such as contact forms, attached documents, legal sections, blogs and news can only be accessed in one language-; abundance of broken links and use of flag icons -not recommended- to access the different localised versions.

Indeed, partial translation has been identified as a recurring problem. Only $36 \%$ of SMEs translate all texts on their websites while $38 \%$ provide a partial translation, that is, on their localised version there is at least one sentence in the original language. The rest of the websites, $26 \%$, are not translated or localised into any language at all.

However, among the websites that are localised to some extent, as shown in Figure 1, there is an important variety of target languages, although Spanish and English are undoubtedly the most used ones.

Moreover, as shown in Table 1, most of the SMEs in the sample only offer their contents in one, two or three languages. Arguably, these companies are not betting on an ambitious internationalisation strategy that allows them to reach a greater number of markets. 


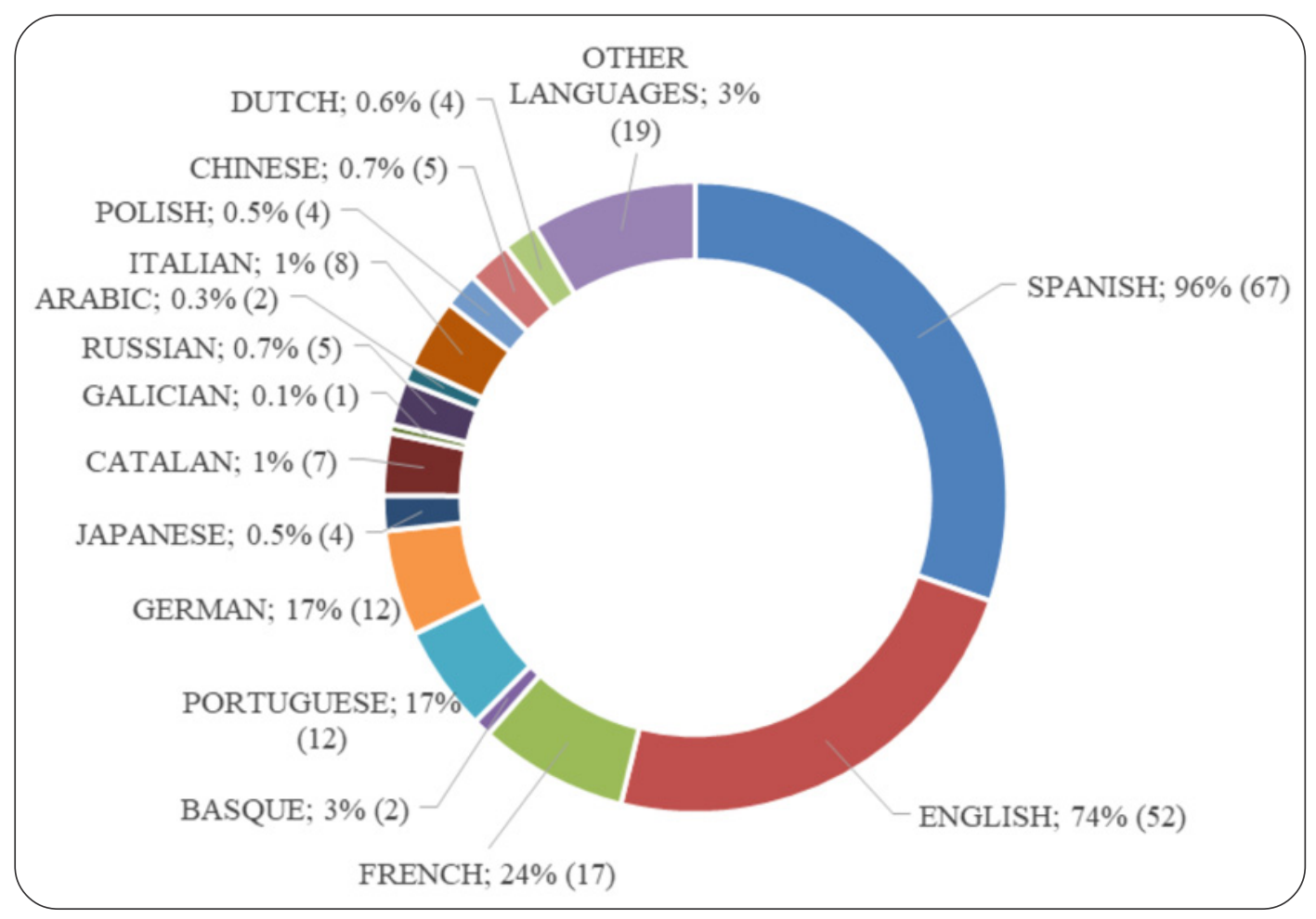

Figure 1. Target languages used in the sample of SME websites

\begin{tabular}{|l|l|}
\hline & Number and \% of SMEs \\
\hline Websites with 1 language & $18(25.7 \%)$ \\
\hline Websites with 2 languages & $25(35.7 \%)$ \\
\hline Websites with 3 languages & $10(14.3 \%)$ \\
\hline Websites with 4 languages & $6(8.6 \%)$ \\
\hline Websites with 5 languages & $5(7.1 \%)$ \\
\hline Websites with 6 languages & $6(8.6 \%)$ \\
\hline
\end{tabular}

Table 1. SMEs in the sample grouped by number of languages on their websites

\section{Recommendations for the Localisation of Corporate Websites}

In light of the results obtained and given that, as previously discussed, website localisation contributes to the internationalisation of companies in general and SMEs in particular, this article puts forward a series of practical recommendations aimed at translators-localizers for the localisation of SME corporate websites. Bearing in mind that linguistic, cultural and technical aspects must be considered when determining the quality of website localisations (Gutiérrez-Artacho and Olvera-Lobo, 2017), the proposed recommendations respond to this classification.

Although it is to be expected that most of these recommendations can be applied to website localisation between very diverse language pairs, most of the examples included involve Spanish and English. The reasons behind this are mainly twofold: the relevance that English currently enjoys as lingua franca and the fact that both languages make up one of the most common language combinations in Spanish SME website localisation, as the results of our sample analysis show.

\section{Linguistic Aspects}

Linguistic aspects involved in website localisation are the area to which Translation studies have probably devoted the most attention (Jiménez Crespo, 2008, 2013). Below is a series of recommendations to help overcome linguistic issues that may arise during website localisation.

\subsection{Content}

The translator-localizer should check for possible translation errors that may unintentionally modify the 
content. Opposite meaning, false meaning, nonsense and omission are only a few of the possible translation errors affecting content that can be made. An error frequently made on websites which can be classified as false meaning is the translation of the English term site map as mapa de la página web. Site maps represent the entire structure of the website, not only of a single web page (as implied by the Spanish term); therefore, the correct translation would be mapa del sitio web. Hurtado Albir (1999) can be consulted for a more thorough list of translation errors.

\subsection{Lexical Aspects}

\subsubsection{Calques, Borrowings and False Cognates}

Due to the influence of the English language on the Web, content writers often incur in calques and borrowings from English when writing in other languages, a practice that should be avoided whenever there is a valid equivalent in the target language. This is the case for English words such as hosting and e-commerce, for which the Spanish equivalents alojamiento web and comercio electrónico can be used. However, there could be commercial and SEOrelated reasons for supporting the use of Anglicisms when these are already widely spread among target speakers. The use of false cognates should also be avoided: *success as a translation for suceso, *localidad for location, *advertisement for advertencia...

\subsubsection{Lack of Terminology Consistency}

Terminology consistency within a website plays a crucial role, helping users become accustomed to the employment of certain terms and expressions and helping them find the information they need quickly (Nielsen, 2000). Thus, alternating between the original and the translated form of the same term ( ${ }^{*}$ mapa del web / site map) or using different expressions to denominate the same website area ( ${ }^{*}$ Acerca de nosotros / sobre nosotros for the English About us) are practices to be avoided.

\subsubsection{Lack of Terminological Precision}

A lack of precision in the terminology used causes confusion and creates a bad impression on receivers. As it would be imprecise to use the word americanos for a group of people from the USA, it would not be appropriate to use the word carreras for the job section of a website related to sport (in Spanish, the word carreras means both careers and racing). Paying attention to these sorts of ambiguities and solving them will increase the quality of the end product.

\subsubsection{Incorrect use of Initials and Acronyms}

As stated by Jiménez Crespo (2008), style manuals often advise against the use of initials on websites because they are not univocal. If translators-localizers decide to use them anyway, they should spell them out accordingly and never mix initials in a language with their translation into another language ( ${ }^{*} A B S$-Sistema Antibloqueo de Ruedas-). Initials should also be pluralised according to rules in the target language. For instance, the plural form of $P C$ in Spanish is invariable $(P C)$ whereas $P C s$ is the most widely accepted form in English.

\subsection{Morphosyntactic and Grammar Aspects 4.3.1 Observing Grammar and Syntactic Rules in the} Target Language. Idiomaticity

Translators-localizers should check for possible subject/ verb or gender agreement mistakes (sometimes arising from a lack of context during the translation process). They should also be careful not to calque source-language syntactic structures that do not sound natural in the target text: *ir atrás (go back), "es operado por (is operated by). As a result of imitating source-language structures, a mistake translators often make is making the subject (usted, tú) explicit in languages that usually drop it, such as Spanish.

\subsection{Style}

Localisation also involves adapting the text to stylistic conventions. In this sense, the general tendency of the target language in terms of sentence length and complexity should be observed. Therefore it would be incorrect to use long sentences with multiple subordinate clauses in English, a language that favours the use of simple and short sentences.

\subsubsection{Inappropriate Register}

As Bolaños (2003) points out, the informal register is predominant on the Internet as a result of the influence of North American culture. On the Web in Spanish, even if the register tends to be more informal than on other media, it is still higher than in English and the use of the formal pronoun usted is often expected. Consequently, the following translations into Spanish are excessively colloquial and do not reflect the appropriate register: *Usted está sujeto a los siguientes Términos y condiciones, que podemos actualizar de vez en cuando sin notificarle a usted de ello; *Cualquier cosa en esta web tiene copyright. It would also be incorrect to alternate between different register levels or between formal and informal pronouns (tú / usted).

\subsection{Orthotypographic Errors}

The orthotypography of the text should follow the rules of the target language. Some aspects to consider are: the use of upper or lower case letters (depending on the language) for titles of complete works or parts of them; the use of the most appropriate type of quotation marks (according to the Spanish language convention, angular quote brackets - «»- are to be used as the first option and only when there is a quote inside a quote should double -"'- - and single quotation marks -"'- be employed), or the right use of question and exclamation marks: in Spanish, both opening and closing marks must be used ( ${ }^{*}$ Viaje a Nueva York!; *Aproveche la oferta!). Typography throughout the text must be consistent.

\subsubsection{Incorrect Spelling (Cacography)}

In order to avoid cacographies, it is advisable to use a spell checker in the reviewing stage of the translated text. 


\subsection{Use of the Right Linguistic Variety}

The use of the right linguistic variety -taking into account differences in orthography, lexicon and morphosyntaxwill not only create a better impression on users but it will also have a positive impact on the number of visits. Users will only be able to access a certain website using a search engine if its content matches the key words they have used on their search. This is why the most advisable option for a company who wants to sell prescription glasses in Mexico would be to use the word lentes instead of other terms that are not as widely used in that country (gafas, anteojos, espejuelos...).

\section{Cultural Aspects}

There are multiple cultural aspects that deserve close attention during a website localisation process (Dr. International, 2003). We describe the most relevant ones in this section.

\subsection{Currency}

It is convenient to adapt prices and other money-related figures to the currency used in the locale. As for the position of the currency symbol, which can be a symbol ('•') or a three-letter code ('EUR'), the convention of the locale must be followed. Thus, in European Spanish (ES_ES), the currency symbol follows the figure and is separated by a space: 15 . Meanwhile, in American Spanish the symbol precedes the figure and is not separated by a space: $\$ 15,429$. Three-letter codes are always separated and come before figures in America: USD 50.82 (RAE and ASALE, 2010). The adaptation of other monetary information such as taxes may also require adapting (Pym, 2011).

\subsection{Date Format}

The date format should also be adapted to the locale. Depending on this, the translator will have to choose among formats such as DD/MM/YYYY (widely used in Spain), MM/DD/YYYY (customary in United States) or YYYY/ MM/DD. The symbol used to separate days, months and years also varies depending on the locale - it can be a slash, a hyphen or a dot (the latter being common in German-speaking countries: DD.MM.AAAA).

A long format, combining numbers and words, can also be used (22 de febrero de 2018). In this case the Spanish convention, as opposed to English and other languages, states that months are written in lower case. Numbers that represent years do not include a dot in Spanish (therefore it would be wrong to write *2.018) (RAE and ASALE, 2010).

\subsection{Time}

The locale will also determine the time format to be employed, and depending on this either the 12-hour or the 24-hour time format will be chosen. In the case of the 12-hour time format, the initials a.m./p.m. may be located before or after the time. The letters that form these initials may or may not be separated by dots $(\mathrm{am} / \mathrm{pm})$ and can be either sedlower or upper case (A.M./P.M.).

The colon (:) is the most widely used character for separating hours, minutes and seconds in Spanish and English-speaking countries, but it does not represent the only possibility, with a number of Asian languages using ideograms instead. Even though clocks are not frequently used on websites, time expressions are common in certain areas such as event news.

\subsection{Numbers}

The character used to separate thousands can be a comma (1,000; USA) or a dot (1.000; Spain, Germany). The same is true for the character used to separate decimals (vice versa for the previously cited examples). The symbol \% may appear before or after the figure, separated by a space or not, or represented by the letters pct.

5.5 Measurements of Length, Mass, Surface, Volume and Temperature, Paper Sizes, etc

Measurement units are another of the main aspects susceptible to variation depending on the locale: that expressed in centimeters on a Spanish website might be best rendered in inches on its localised version in English, for example. Regardless of the unit used, it is crucial to state it clearly in order to avoid misunderstandings (38 !, $75 \mathrm{~kg}$, an A4 sheet of paper).

\subsection{Phone Numbers}

They should include the international call prefix (00 34 / +34 for Spain) in order to facilitate communication with international users.

\subsection{Forms}

In order to localize contact forms, which can be found on many websites, a number of aspects should be taken into account:

- 'Province', 'autonomous community' or 'state' fields: filling in these fields should be optional since they may not be relevant depending on the user's country of origin.

- 'Post/Zip code' field: the number of digits that can be introduced should be flexible and allow letters.

- 'Phone' field: should allow a very flexible number of digits.

- 'Surname' field: should be able to accommodate one or more surnames. Consequently, the correct name of the field would be 'surname(s)' or 'apellido(s)' in Spanish (Jiménez Crespo, 2008).

\subsection{Visual Aspects with Cultural Signification}

It is very advisable to consider the possible cultural weight implicit in visual elements present on the website. Flags should be avoided in areas such as the language selector because they hardly ever represent all the speakers of a language, and this can lead to controversy. As for the colour selection, they rarely pose problems between close cultures. In this respect, McCandless (2014) makes a 
very interesting contribution by proposing a palette with appropriate colours to express ideas and feelings in different cultures and/or geographical areas. It should not be forgotten that there can be images with negative connotations for the target culture and that some icons might need adaptation.

\subsection{Links to other Websites}

Whenever possible, links to other websites should redirect to their version in the target language of our website. If this version does not exist, it is advisable to inform the user about the language in which the context of the link is written. For example, www.rae.es (in Spanish).

\subsection{Customer Service (Availability in Various Languages)}

Ideally, localisation should cover all aspects of interaction with users, including customer service, which can be offered through different means ranging from telephone and email to conversational bots (also called chatbots).

\subsection{Unnecessary and/or Incorrect Explanations}

When there are differences between the shared knowledge of the source and target culture, it may be necessary to provide additional explanations in order to make it easier for users to understand the information offered. This is a technique known as amplification (Hurtado Albir, 2007). For example, on a web page about tourism in Spain localised into Chinese, it could be very appropriate to specify the geographical situation of Spanish cities: Oviedo, a city in the north of Spain... It would be a mistake, however, to add information that is incorrect or whose knowledge can be presupposed to receivers. For example, on a website aimed at users from the health sector, it would probably be unnecessary to define terms such as apoplexy or rhinoplasty.

\subsection{News and Products Adapted to the Locale}

The news section should be translated just like the rest of the website. The ideal option would be to publish news items relevant to the target audience - for example, providing information on events to take place in the region, or announcing the opening of a new business branch in the corresponding country. In the case of websites where products are sold, it would be most appropriate to only offer products available in the region of the locale, as the company IKEA does on their website: www.ikea.com.

\subsection{Localising Online Presence on Social Media and Search Engines}

It is highly recommendable to have independent social media profiles adapted to each locale where only products, news and event announcements that are relevant to that particular audience are offered. Additionally, there could be specific social media or search engines that are popular among the target audience, and where having a profile would be particularly interesting for a company. In Russia, for example, VK has a popularity similar to that of Facebook.

\subsection{Legal Provisions}

As pointed out by Corte (2002), there can be great variations from one country to another in aspects such as copyright legislation, personal data protection or conditions of use, so it is worth turning to professional legal advice when localising the corresponding website sections. Translators-localizers should take into account that legal provisions may exist that ban the modification and translation of visual elements such as the logo or emblem of a brand or institution.

\subsection{Conventions and Standards}

Translators-localizers must be aware of website conventions and standards, ranging from those pertaining to terminology, to website appearance and structure. These conventions "contribute enormously to reduce user confusion and improve usability" (Fernández Costales, 2010). In this way, it would be erroneous to use the expression Send an e-mail to refer to the section typically known as Contact (Fernández Costales, 2010).

\section{Technical Aspects}

\subsection{Language Selection}

We have already mentioned the IKEA website (www.ikea.com) as an example of website where the products offered are adapted to the region where the consumer is located. This is done by requesting that users select both their region and language on the home page; thus, the version for Belgium can be accessed both in Dutch and French. This is an excellent example of how to build a website taking into account regional and language differences. However, one possible improvement could be to add more languages per country or region (for example, a localisation of the website for Germany into English would undoubtedly be interesting for many consumers who live in that country but do not speak German).

Likewise, the language selector should be accessible from any web page and users should not be redirected to the home page when choosing a different language.

\subsection{Search within the Website}

In addition to setting up an internal search engine that works properly, users should be allowed to choose between searching within contents in one of the available languages or all of them.

\subsection{Character Encoding, Bidirectional Writing}

Unicode is the only character encoding system able to represent characters from almost any language, including Asian ones. Unicode can be used on a website by including a meta tag on the header section of the source code that declares that the encoding will be UTF-8 (8-bit Unicode transformation format).

In addition, web developers should take into account the possibility of the target languages into which the website is to be translated using right-to-left text (Arabic, Hebrew) to avoid localisation problems, singand ensure the correct 
display of content.

\subsection{Same content for All Versions in all Languages}

All localised versions of the website should provide the same information as the original version whenever this information is relevant to the target audience.

\subsection{Translation of Downloadable Documents}

Users should be provided with versions of downloadable documents (PDF forms, .doc files) adapted to each locale.

\subsection{Translation of Web Page Names}

Words included in the URL should appear in the same language in which the content is written: note http:// locweb.aulaint.es/quienes-somos versus http:// locweb.aulaint.es/fr/qui-sommes-nous.

The language and language variety used should equally be declared at the beginning of the HTML document on each web page. For example, the HTML attribute for European Spain would be <html lang="es" $>$. If any part (word, sentence or paragraph) within a web page appears in a different language, the code should reflect it. For example, a paragraph in Spanish within a web page in English would be marked with the paragraph tag followed by the language attribute: $<p$ lang="es" $>$ (Andreu-Vall and Marcos, 2012).

\subsection{Content Management System with Multilingual Functions}

If a content management system (CMS) is used (WordPress, Joomla), its compatibility with the target languages should be checked prior to the beginning of the localisation process. In this regard, it is important to obtain prior information on plugins for incorporating translations into the website. The theme used for the website should also support several languages. (Cova, 2016).

\subsection{Responsive Web Design}

Responsive web design, a term coined by Marcotte (2010), is the practice of building websites suitable for working on any device, whether mobile or not. When a website is developed using a responsive design, it is correctly displayed on computers, mobile phones and tablets.

\subsection{Audiovisual Content}

\subsubsection{Images, Audio and Video}

Text inside of pictures can be localised using a graphics editor such as GIMP or Adobe Photoshop. Mata Pastor (2009, 2009b) can be consulted for a detailed study on the topic.

Audio and video files on the website should also be translated into the target languages, either using subtitles or dubbing. Cultural aspects should also be taken into account - for instance, Muslim-majority countries favour the use of masculine voices over feminine ones for dubbing (Martin, 2002).

\subsubsection{Accessibility}

Web accessibility is a very broad area whose main objective is to enable access to the Web by the largest possible number of people, including the disabled or the elderly. In order to make a website accessible, some key points to consider are:

- The HTML 'alt' and 'title' attribute must be translated. Not only will this optimize content indexing and therefore improve the website ranking on search engines, but it will also allow visually disabled people to identify the content of pictures using special reading software (Andreu-Vall and Marcos, 2012). Besides what has been mentioned in a previous section, another reason why using flags in the language selector area is advised against is because they impose accessibility barriers for visually impaired users, unless they are provided with a text alternative that allows them to identify the language they want to select (Rodríguez Vázquez, 2015).

- The level of accessibility of a website can be checked using specific software for this purpose. An example is aDesigner.

- The Web Content Accessibility Guidelines (WCAG), produced by the World Wide Web Consortium (W3C), are a series of recommendations for Web content accessibility. These are internationally recognised guidelines whose objective is to improve Internet access (W3C, 2008).

- In a broader conception of accessibility, users who do not have fast Internet connection might have problems to access websites with a large number of pictures and audiovisual material. If this is the case, it might be advisable to consider removing pictures with a merely decorative function to enhance access to the information provided (Fernández Costales, 2010).

\subsection{Website Structure}

Website structure is related to the concept of usability. In the context of Internet, a website has a high level of usability if it is easy for users to find a certain piece of information on it. In order to achieve this goal, attention must be paid to the way information is structured and changes should be introduced if necessary and provided the localisation assignment makes it possible.

In this regard, it must be borne in mind that users typically scan on-screen information instead of reading it from beginning to end, as they usually do with print text. Furthermore, users only read between $20 \%$ and $28 \%$ of the content of a web page and their reading speed is up to $25 \%$ slower on a screen as opposed to paper (Nielsen, 2008). In consequence, it is essential to use simple, direct language with short and concise sentences. Information should also be organised following an inverted pyramid structure and expressing a single idea on each paragraph. Likewise, it is convenient to write up to $50 \%$ less than in other media, divide up the text in different documents 
connected by links and write short paragraphs so that the desired information can be found quickly (Nielsen, 2000).

Concerning general website structure, Nielsen (2004) interestingly points out that $80 \%$ of websites use a similar design to fulfil users' expectations. A clear and familiar structure will improve website usability as a whole.

\subsection{Search Engine Optimisation and Tags}

As already pointed out by other studies, it is convenient for translators to be aware of search engine optimisation (SEO) techniques and it is advisable to adapt website contents both to users and search engines, even by means of the so-called transcreation or rewriting of the text (Ramírez Pereda and Varela Salinas, 2017). Although SEO is a very broad area that goes beyond the objectives of this paper, it is important to point out that there are certain HTML tags and attributes whose translation has an effect on the website ranking on search engines:

- Translation of the 'title' tag (head element): it is the web page title as it appears on the top area of the browser and on the search engine results. Translating it makes it easier for various types of audiences to identify the page and it also allows search engine robots to index the title in the corresponding language.

- Translation of the 'description' and 'keywords' meta tags: browsers do not display them because they are located in the head element of the source code, but search engine robots can access and index them. Additionally, the information contained in the 'description' tag is oftentimes displayed on the result page of search engines as a summary of the page content. The 'keywords' tag should be translated but it is not as relevant for the website ranking as it used to be in the past. Nowadays, search engines rank websites using much more sophisticated methods that allow them to interpret web page content - for example, Google favours naturally written content, automatically determines keywords and takes into account word variations (gender, number).

- Translation of alt and title attributes: see section 3.9.2.

- Translation of the link 'title' attribute, which displays information when users hover over links. Search engine robots can access these, too.

Google enjoys an almost worldwide popularity. However, there are certain markets where other search engines are just as widely used or even more so, as is the case with Yandex in Russia or Yahoo! in Japan. In such cases it is convenient to check how the website that is being localised ranks on these search engines and make efforts to improve its ranking.

\subsection{Visualisation}

When text is translated, its length tends to increase or decrease. For instance, in translations from English into other languages, text length usually increases between $20 \%$ and $30 \%$ (Chandler, 2005: 5). Although this factor is usually more problematic in software localisation, in website localisation this might involve the need to resize certain areas - e.g. the site menu - so that text is correctly displayed.

\section{Validation Stage}

A website localisation project should include a stage where the quality of the end product is checked. Such a stage should comprise a number of verifications such as the following, based on Sandrini (2008) and Corte (2002):

- Linguistic check: all the text must be translated and the quality of the target text must be satisfactory from a linguistic point of view.

- Functional and technical check: the localised website must work exactly in the same way as the original. In order to check this, various aspects must be verified - for instance, all links and web forms must work and attached files must download correctly. It is advisable to carry out these checks using several browsers and, if possible, several devices.

- Checking the appearance of the localised website: all text must be visible, content inside of pictures must be translated and formatting must be appropriate. Dialog boxes and dynamically generated texts must be checked, too.

\section{Conclusions}

As we have argued throughout this article, website localisation processes encompass a vast number of aspects that go beyond merely linguistic matters. In order to ensure the acceptance and success of the final product in the target market, localisation entails, among other issues, the adaptation of the source text to the target culture (e.g. by converting date formats, currencies or units of measurement), content and/or style modifications as well as adding, omitting or summarising information depending on its relevance for the target audience (Pierini, 2007). Website localisation, framed in the set of GILT processes, is an unavoidable step for those SMEs that want to introduce their business into foreign markets by offering information, products or services on their websites. Localisation carried out by specialised professionals does not only allow companies to communicate with customers from other sociocultural contexts, but it also enhances the usability of their website, improves their corporate image and creates a positive impression on users and potential customers.

Finally, the multiple relevant aspects in a website localisation process should be taken into account from the first stages of the website development in order to avoid unnecessary costs and deficiencies in the end result. Ideally, the different agents involved in the creation of the 
product (localizers, customers, web developers) should work in close collaboration, since only in this way can the end product reach a satisfactory quality level.

\section{Acknowledgment}

This work was supported by the Spanish Ministry of Science and Innovation under the research project CSO2015-64532-R, partially funded by the FEDER program of the European Union.

\section{References}

[1] Andreu-Vall, M., Marcos, M. C. (2012). Evaluación de sitios web multilingües: metodología y herramienta heurística. El profesional de la información 21 (3) 254 260.

[2] Baack, D.W., Singh, N. (2007). Culture and web communications. Journal of Business Research, 60 (3) 181-8.

[3] Bolaños Medina, A. (2003). Dificultades y estrategias de la localización de sitios web comerciales del inglés al español. In: S. Posteguillo et al. (Eds.), Internet in Linguistics, Translation and Literary Studies, p. 241-262. Castelló de la Plana: Publicacions de la Universitat Jaume I.

[4] Cadieux, P., Esselink, B. (2002). GILT: Globalization, Internationalization, Localization, Translation. Globalization Insider 11 (1.5) 1-5.

[5] Corte, N. (2002). Localización e internacionalización de sitios web. Revista Tradumàtica: traducció $i$ tecnologies de la información i la comunicació 1. 1-8.

[6] Cova, E. (2016). Translation challenges in the localization of web applications. Sendebar 27. 235-266.

[7] Dr. International (Microsoft Corporation) (2003). Developing International Software. Redmond, Washington: Microsoft Press.

[8] Dunne, K. (2006). A Copernican Revolution. In: K. Dunne (Ed.), Perspectives on Localization, p. 1-11. AmsterdamPhiladelfia: John Benjamins.

[9] Esselink, B. (2006). The evolution of localization. In. A. Pym et al. (Eds.), Translation Technology and its Teaching, p. 21-30. Tarragona: Intercultural Studies Group.

[10] Esselink, B. (2001). A Practical Guide to Localization. Amsterdam-Philadelfia: John Benjamins.

[11] Fernández Costales, A. (2010). Traducción, localización e internacionalización. El caso de las páginas web universitarias. PhD thesis, Universidad de Oviedo, Spain.

[12] General Secretariat of Industry and Small and Medium Enterprises (Spanish Ministry of Economy, Industry and Competitivity) (2018). Cifras PYME, datos febrero 2018, http://www.ipyme.org/Publicaciones/CifrasPYMEfebrero2018.pdf.
[13] González, D., Marcos, M.C. (2013). Responsive web design: diseño multidispositivo para mejorar la experiencia de usuario. BiD: textos universitaris de biblioteconomia $i$ documentació 31. 1-10.

[14] Gutiérrez-Artacho, J., Olvera-Lobo, M.D. (2017). El uso del método Delphi como herramienta de evaluación consensuada en la didáctica de la traducción: el perfil del traductor-localizador. In: Congreso CUICIID 2017: Congreso Universitario Internacional sobre la comunicación en la profesión y en la Universidad de hoy: Contenidos, Investigación, Innovación y Docencia, http:// digibug.ugr.es/handle/10481/48752?mode=full. (October).

[15] Hurtado Albir, A. (2001). Traducción y traductología: introducción a la traductología. Madrid: Cátedra.

[16] Hurtado Albir, A. (1999). Enseñar a traducir: metodología en la formación de traductores e intérpretes. Teoría y fichas prácticas. Madrid: Edelsa.

[17] Jiménez Crespo, M. A. (2013). Translation and Web Localization. London: Routledge.

[18] Jiménez Crespo, M. A. (2008). El proceso de localización web: estudio contrastivo de un corpus comparable del género sitio web corporativo. PhD thesis, Universidad de Granada, Spain.

[19] LISA (2003). The Localization Industry Primer. Geneva: Localization Industry Standards Association.

[20] Lommel, A. (2007). LISA Globalization Industry Primer. Romainmôtier: LISA.

[21] London Stock Exchange Group (2017). 1000 Companies to Inspire Europe - 2017 Report, https:// www.lseg.com/resources/1000-companies-inspire/2017report-1000-companies-europe.

[22] Marcotte, E. (2010). Responsive Web Design, http:/ /alistapart.com/article/responsive-web-design.

[23] Marín Dueñas, P. P., Lasso de la Vega González, M. C. (2017). La efectividad de las páginas web en la comunicación empresarial de las pequeñas y medianas empresas. Un estudio en PYMES de la provincia de Cádiz. Zer 22 (42) 53-71.

[24] Martin, M. (2002). La localización de software: una especialidad incipiente en los Estudios de Traducción. In: J.M. Bravo (Ed.), Nuevas perspectivas de los estudios de Traducción, p. 295-313. Valladolid: Universidad de Valladolid.

[25] Pastor, Mata. M. (2009a). Algunas pautas para el tratamiento de imágenes y contenido gráfico en proyectos de localización (I). Entreculturas: revista de traducción y comunicación intercultural 1.513-532.

[26] Pastor, Mata. M. (2009b). Algunas pautas para el tratamiento de imágenes y contenido gráfico en proyectos de localización (II). Entreculturas: revista de traducción y comunicación intercultural 1.533-569.

[27] McCandless, D. (2014). Knowledge is Beautiful. London: HarperCollins. 
[28] Nida, E. (1945). Linguistics and Ethnology in Translation-Problems. WORD 1 (2) 194-208.

[29] Nielsen, J. (2008). How little do users read? http:// www.useit.com/alertbox/percent-text-read.html.

[30] Nielsen, J. (2004). The need for Web Design Standards. http://www.useit.com/alertbox/20040913.html.

[31] Nielsen, J. (2000). Designing Web Usability. Indianapolis, Indiana: New Riders Publishing.

[32] Pierini, P. (2007). Quality in web translation: An investigation into UK and Italian tourism websites. The Journal of Specialised Translation, 8. 85-103.

[33] Pym, A. (2011). Website localization. In: K. Malmkjaer, K. Windle (Eds.), The Oxford Handbook of Translation Studies, p. 410-424. Oxford University Press.

[34] Pereda, Ramírez., L., Salinas, Varela., M. J. (2017). Traducción y optimización en buscadores (SEO): de la traducción a la transcreación. Sendebar 28. 261-283.

[35] Real Academia Española and Asociación de Academias de la Lengua Española (2010). Ortografía de la lengua española. Madrid: Espasa Calpe.

[36] Vázquez, Rodríguez. S. (2015). Exploring current accessibility challenges in the multilingual web for visuallyimpaired users. In: Proceedings of the 24th International Conference on World Wide Web, p. 871-873. New York: ACM.

[37] Sandrini, P. (2008). Localization and Translation. In: H. Gerzymisch-Arbogast et al. (Eds.), MuTra Journal, Vol 2. LSP Translation Scenarios. Selected Contributions to the EU Marie Curie Conference Vienna 2007, p.167-191. Saarbrücken: ATRC.

[38] Singh, N., Pereira, A. (2005). The Culturally Customized Website. Amsterdam: Elsevier.

[39] Sánchez, Tercedor., M. I. (2005). Aspectos culturales en la localización de productos multimedia. Quaderns, 12. 151-160.

[40] World Wide Web Consortium. (2008). Web Content Accessibility Guidelines (WCAG) 2.0., https://www.w3.org/ TR/WCAG20/.

[41] You, W. (2017). Globalization, translation and soft power. A Chinese perspective. Babel, 63 (4) 463-485.

[42] Yunker, J. (2002). Beyond Borders: Web Globalization Strategies. Indianápolis, Indiana: New Riders. 